\title{
A Comparison between Organic and Conventional Olive Farming in Messenia, Greece
}

\author{
Håkan Berg 1,* , Giorgos Maneas ${ }^{1,2}$ and Amanda Salguero Engström ${ }^{1}$ \\ 1 Department of Physical Geography, Stockholm University, 10691 Stockholm, Sweden; \\ giorgos.maneas@natgeo.su.se (G.M.); amandase92@gmail.com (A.S.E.) \\ 2 Navarino Environmental Observatory, Navarino dunes, Costa Navarino, 24001 Messinia, Greece \\ * Correspondence: hakan.berg@natgeo.su.se; Tel.: +46-702559069
}

Received: 15 May 2018; Accepted: 4 July 2018; Published: 9 July 2018

\begin{abstract}
Olive farming is one of the most important occupations in Messenia, Greece. The region is considered the largest olive producer in the country and it is recognized as a Protected Designation of Origin (PDO) for Kalamata olive oil, which is considered extra fine. In response to the declining trend of organic olive farming in Greece, this study assesses to what extent organic olive farming in Messenia provides a financially and environmentally competitive alternative to conventional olive farming. In this study, 39 olive farmers (23 conventional and 16 organic) participated in interviews based on questionnaires. The results showed that organic olive farming is significantly more profitable than conventional farming, primarily because of a higher price for organic olive oil. Despite this, the majority of the conventional farmers perceived a low profit from organic farming as the main constraint to organic olive farming. All farmers agreed that organic olive farming contributed to a better environment, health and quality of olive oil. Organic farmers used fewer synthetic pesticides and fertilizers and applied more environmentally-friendly ground vegetation management techniques than conventional farmers. Overall, organic farming was found to provide a competitive and sustainable alternative to conventional olive farming in Messenia.
\end{abstract}

Keywords: sustainable olive farming; organic produce; conventional produce; food safety

\section{Introduction}

Olive farming is one of the most significant sources of income for agricultural areas in the Mediterranean basin, and the olive oil industry is an important part of the Greek agricultural sector [1-3]. Traditionally cultivated olive groves provide important cultural and natural value, but more intensively farmed olive areas can also generate health and environmental impacts from pesticides, fertilizers and soil erosion [1,4-6]. These drawbacks can make farms less competitive on the market by impacting on their sustainability and product quality, and there is a need to improve the olive-growing sector's management practices, by optimizing their resource use in a more effective and sustainable way [5]. Innovations need to respond to new sustainability requirements, initiated through public policies (eco-conditionality) and at the private level by consumers and citizens that are increasingly concerned with the environment and human health [1].

In this context, organic olive farming has previously been proposed as a strategic and sustainable option to conventional farming, with benefits for the environment, health and product quality. For example, a meta-analysis of 94 studies on the effect of organic farming on biodiversity has shown that biodiversity generally is $30 \%$ higher in organic farmland than in conventional [7]. Organic farming means that no chemical pest control methods and no mineral fertilizers that are not naturally-derived are allowed [8]. The organic farmers should also use practices that prevent soil erosion and maintain the soil organic matter (SOM) levels [8]. There were 509 million hectares of organic agricultural land in 
the world in 2015, a number that has risen significantly since 1999, when there were only 11 million hectares [9]. Still, the organic share of total agricultural land was not larger than 1.1\% in 2015 [9].

Europe has seen a steady increase of organic agricultural land [9]. Austria and Sweden top the list of the European Union (EU) member countries with the highest share of the organic area in Europe [10]. Greece is placed in the middle of the list, with approximately $6 \%$ of Europe's organic agricultural area [10]. In 2011, olive groves made up 31\% of all the organic permanent crop area in Europe, and Greece was one of the three most important olive-growing countries in Europe [10].

The area with olive groves in Greece has increased constantly during the last quarter century, as a result of the planting of new high-density farms [4]. Farms of olive oil have expanded in many semi-mountainous and coastal areas (mainly in Crete and the Peloponnese region). The tendency is to intensify production through mechanization, levelling of the land, use of drip irrigation and increased use of external inputs, while the mixed cultivation of olive trees with other trees or arable crops is disappearing [4].

The challenges of growing olive trees are, among other things, to provide them with water and nutrients and to control pests. The hot, dry summers in southern Greece cause high evapotranspiration, and irrigation is therefore sometimes required to obtain optimal yields, even though olive trees are considered drought resistant [11]. The olive fly (Dacus oleae) is the main pest affecting the olive plantations, causing problems both with lower olive yields and with lower quality of the oil [4,12-14]. Insecticides are commonly applied to olive groves to control pests, such as Dacus oleae, Saissetia oleae and Prays oleae, and to increase the number and size of olives and the subsequent yields $[4,13,15]$. Also, herbicides are commonly used against weeds, and there is a risk that these pesticides contaminate the quality of the olive oil $[4,15]$. The pesticides could also affect the farmers' health and cause environmental impacts, such as contamination of water and soil and a decline in biodiversity [4-6]. There might also be a problem with the pesticides killing the natural enemies of the pests, which makes the pest problem even bigger [4].

Soil erosion is also considered as one of the main environmental impacts associated with intensive olive farming, causing the runoff of topsoil, fertilizers and pesticides into water sources [4]. This is caused by the removal of all the natural ground vegetation by tillage or herbicide use, which is commonly used in conventional olive farming to reduce the competition for water and nutrients [16-18]. However, the practice of totally removing the ground cover might have larger negative than positive effects on olive groves, because erosion reduces the soil's productive capacity, which in turn leads to greater use of fertilizers [4].

Organic olive cultivation more often involves maintaining a vegetative cover on the ground and less use of tillage and pesticides than conventional olive cultivation [19], which, in addition to reducing soil erosion, has a positive effect on biodiversity $[17,18]$. About $7 \%$ of the Greek olive groves are organic [10]. Since 2008, the organic olive area in Greece has decreased, a trend that differs from the other big olive growing countries-Spain, Italy and Portugal [10]. At the same time, there is an increasing demand for organic olive oil, which can be sold for higher prices than the conventionally produced oil [10]. There are studies indicating that organic olive farming can be equal or more profitable than conventional olive farming [20-22]. The advantages of organic olive farming seem to be a combination of higher oil prices, higher subsidies and lower production costs [20-22]. It has also been shown that reduced tillage, which is common in organic olive farming, can lead to higher yields [23].

Thus, considering the declining trend of organic olive farming in Greece, despite an increasing demand for organic olive oil, it is urgent to investigate to what extent organic olive farming in Messenia could provide a financially competitive alternative to conventional olive farming. By comparing agriculture practices and the farmers' attitudes to organic and conventional olive farming, the study also aims to compare the farming systems' environmental sustainability and to assess the farmers' perceptions of major benefits and difficulties with organic olive farming. 


\section{Materials and Methods}

\subsection{Study Area}

Messenia is a regional unit in the Peloponnese peninsula in south-west Greece and is considered to be one of the most important olive-growing regions in the country [24]. It has a population of 234,700 inhabitants and an area of $2991 \mathrm{~km}^{2}$ [25]. There are six municipalities in Messenia, including Pylos-Nestor and Trifylia, where the study was conducted (Figure 1). Olive farming is one of the most important occupations in Messenia, with $71 \%$ of the agricultural area and $20 \%$ of the total area in the region consisting of olive groves [26].

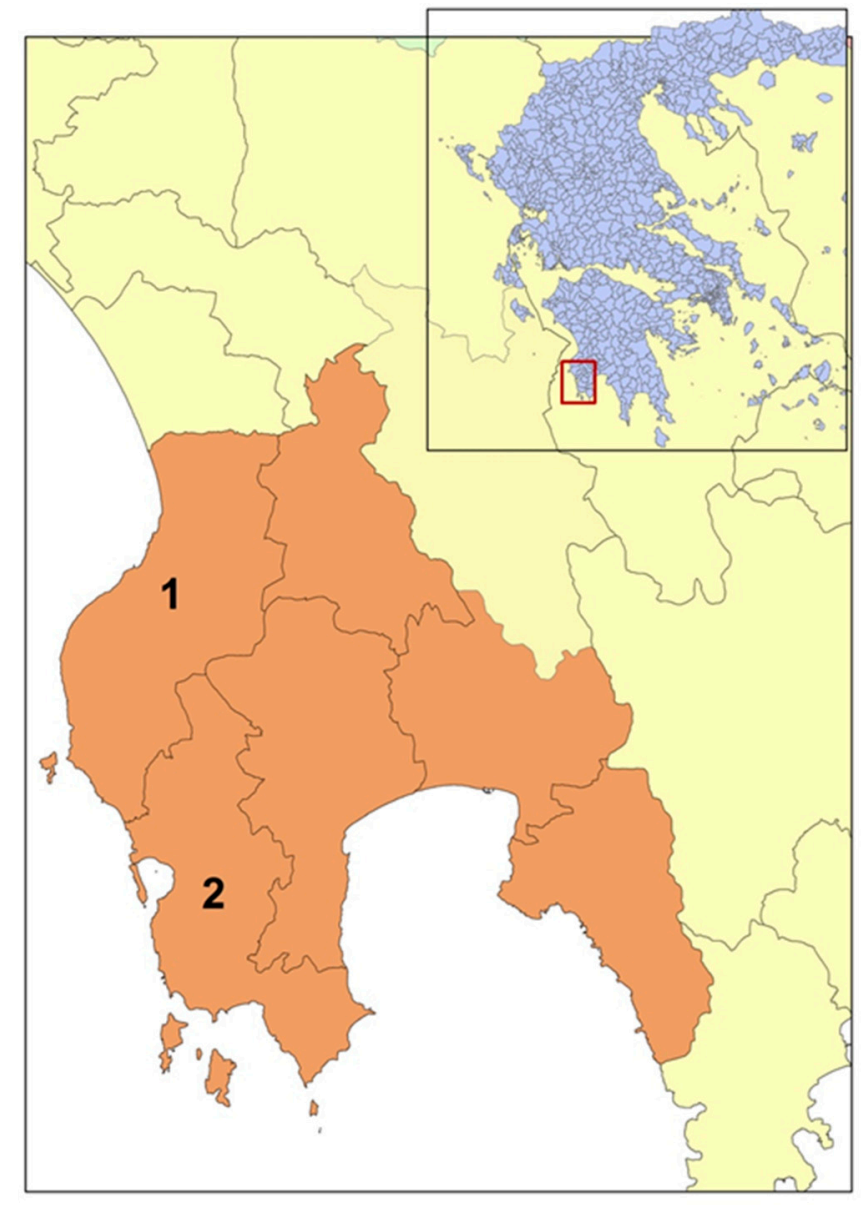

Figure 1. Messsenia with its six municipalities in south-western Greece. The interviewed farmers belonged to the Pylos-Nestor (No. 2, 36 farmers) and Trifylia (No. 1, 2 farmers) municipalities.

The climate in the Messenia region is classified as Csa (typical Mediterranean climate) in the Köppen-Geiger system, which means dry, hot summers [27], and provides thus a suitable climate for olive cultivation. The climatic conditions, together with an extensive river system, have contributed to the formation of fertile soils, which are ideal for the cultivation of olive groves producing supreme quality olives and olive oil. Since July 2015, the entire region of Messenia has been recognized as a Protected Designation of Origin (PDO) for Kalamata olive oil, which is considered extra fine [28].

Messenia is one of the oldest olive cultivation areas in Greece, and olive cultivation has been the main income for its inhabitants for centuries [24]. The local olive variety is Koroneiki, a low-stem type that is used for olive oil production and, therefore, the fruits do not have to become so big in comparison with table olives and consequently do not need the same amount of water [23]. Biodiversity tends to be high in traditionally cultivated olive groves, which provides a variety of habitats supporting a diversity 
of wildlife including reptiles, butterflies and other invertebrates, birds and mammals, contributing to the unique biodiversity of the area [4].

\subsection{Farmers Survey}

A total of 39 olive farmers participated in interviews based on questionnaires. The questionnaires were developed through consultation with local agronomists who worked both with conventional and organic olive farmers. The agronomists also provided help with contacting olive farmers who were willing to participate in the study. Any olive farmer who was willing to participate in the study was accepted and no farmers were excluded, although the study aimed to balance the number of conventional and organic farmers. The interviews were conducted as a combination of 'survey interviews' and 'qualitative interviews' [29]. In a survey interview, the informants are viewed mostly as providers of information, while a qualitative interview searches for meanings and perceptions rather than hard facts [29]. The aim of the questionnaires/interviews was to gain information about the expenses and income of the farmers, the usage of fertilizers, pesticides and other agriculture practices, and the farmers' perception of organic olive farming. The interviews were conducted in Greek, as some of the farmers were weak in English. Among the interviewed farmers, 23 practiced conventional olive farming and 16 practiced organic olive farming.

\subsection{Statistical Analysis}

Differences between conventional and organic olive farmers were investigated using one-way analysis of variance (ANOVA) with Turkey's HSD (honestly significant difference) used as the post-ANOVA test. Data was checked for normal distribution and transformed when necessary, before the statistical analyses were performed. SPSS for windows (Version 17.0; SPSS, Chicago, IL, USA) was used to analyze the data.

\section{Results}

On an average, organic farmers had larger farms than conventional farmers. They had a higher yield of olive oil per tree, but a slightly lower yield per hectare because of a lower number of trees per hectare (Table 1).

Organic farmers had a somewhat shorter experience of olive farming than conventional farmers (Table 2). Almost $90 \%$ of the organic farmers had more than 7 years of experience of working with organic olive certification (Table 2); 30\% of the conventional farmers did not want to start organic farming, while some $50 \%$ were uncertain and $20 \%$ wanted to start organic olive farming (Table 2).

Table 1. Farming characteristics and olive oil yields among organic $(n=16)$ and conventional $(n=23)$ olive farmers in Messenia, Greece. The asterisks $\left(^{*}\right)$ mark statistically significant differences $(<0.05)$ between the two groups of farmers.

\begin{tabular}{lcc}
\hline & Organic Famers & Conventional Farmers \\
\hline Farm Size (ha) & 6.9 & 5.4 \\
Std. Deviation & 3.2 & 3.6 \\
Trees Per Hectare & 182 & 212 \\
Std. Deviation & 54 & 76 \\
Yield Olive Oil (L/ha) & 1088 & 1137 \\
Std. Deviation & 197 & 325 \\
Price Olive Oil (€/L) & $4.5^{*}$ & 3.3 \\
Std. Deviation & 0.6 & 0.3 \\
Subsidies (€/ha) & 969 & 695 \\
Std. Deviation & 501 & 396 \\
Percentage Income from Olive Farming $(\%)$ & $88^{*}$ & 66 \\
Std. Deviation & 21 & 25 \\
\hline
\end{tabular}


Table 2. Experience of olive farming among organic $(n=16)$ and conventional $(n=23)$ olive farmers in Messenia, Greece.

\begin{tabular}{lcc}
\hline & Organic Famers & Conventional Farmers \\
\hline Years of Experience in Olive Farming & & \\
(\% Farmers) & 0 & 13 \\
1 to 5 & 12 & 9 \\
6 to 10 & 35 & 30 \\
11 to 20 & 35 & 22 \\
21 to 30 & 6 & \\
31 to 40 & 12 & \\
$40+$ & & \\
Years of Organic Certification & & \\
(\% Organic Farmers) & 6 & \\
1 to 3 & 6 & \\
4 to 6 & 50 & \\
7 to 10 & 33 & 22 \\
11 to 15 & 6 & 20 \\
16 to 20 & 0 & 48 \\
$20+$ & & \\
\hline Interest in Starting Organic Farming & & \\
(\% Conventional Farmers) & & \\
Yes & & \\
No & & \\
Uncertain & & \\
\hline
\end{tabular}

Both organic and conventional farmers believed that organic olive farming contributed to a better environment, health and quality of products (Figure 2). A slightly larger proportion of the organic farmers also felt it was easier to sell organic olive oil and that this contributed to overall economic benefits (Figure 2).

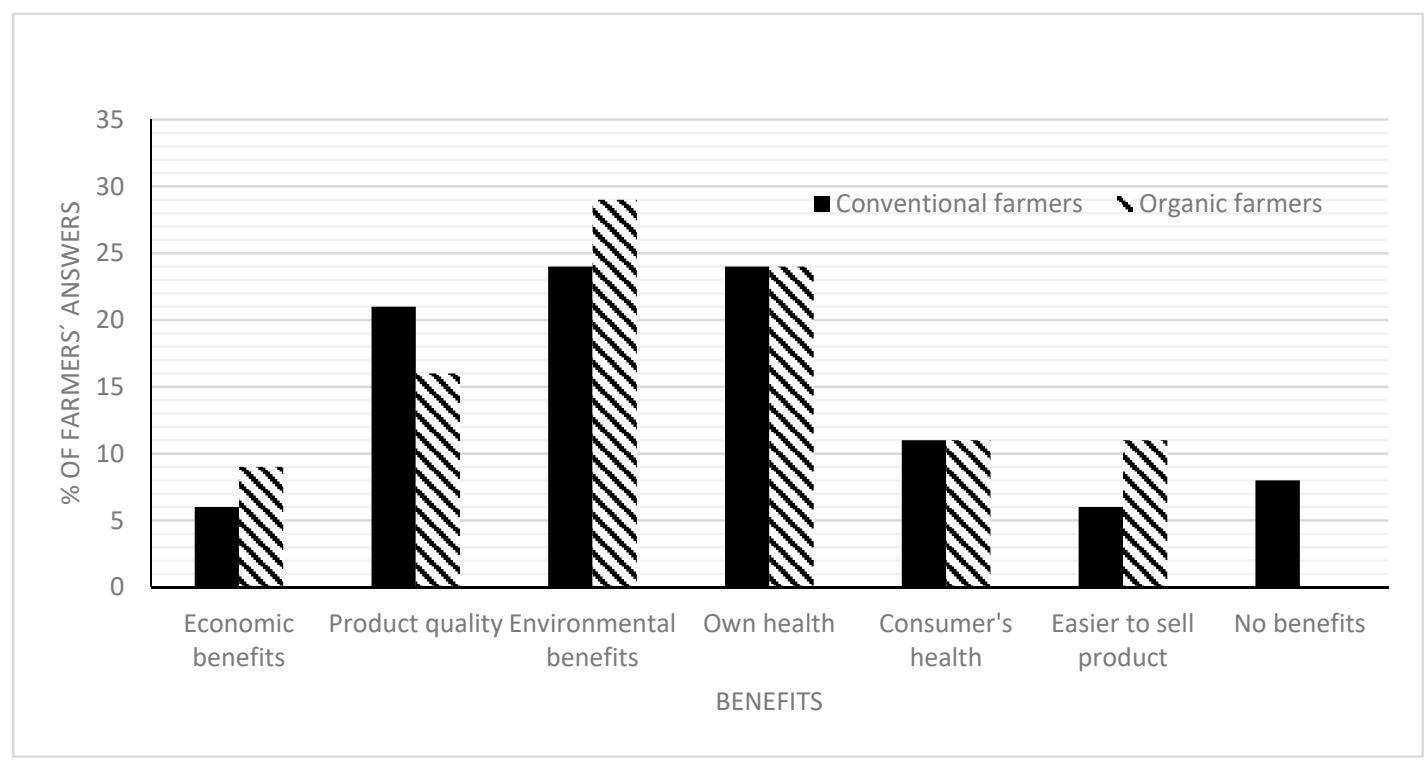

Figure 2. Benefits of organic farming as perceived (open-ended question) by organic $(n=16)$ and conventional $(n=23)$ olive farmers in in Messenia, Greece.

Conventional farmers perceived a low profit as the most critical difficulty with organic farming, which was not shared with the organic farmers (Figure 3). They were also worried about difficulties in controlling pests and finding suitable fertilizers that would be allowed in organic olive farming. 
This was of less concern among the organic farmers. However, organic farmers were somewhat less satisfied with their pesticides and fertilizers ( 6.6 and 7.2 out of 10 scores, respectively) compared to the conventional farmers (7.8 and 8.4 out of 10 scores, respectively). Both groups of farmers felt that there was a lack of information and knowledge about organic farming, which was seen as a barrier to adopting the system (Figure 3). The main concern among organic farmers was the high time demand, although there was no difference in the labor cost between organic and conventional olive farming (909 and $936 € /$ ha/year, respectively).

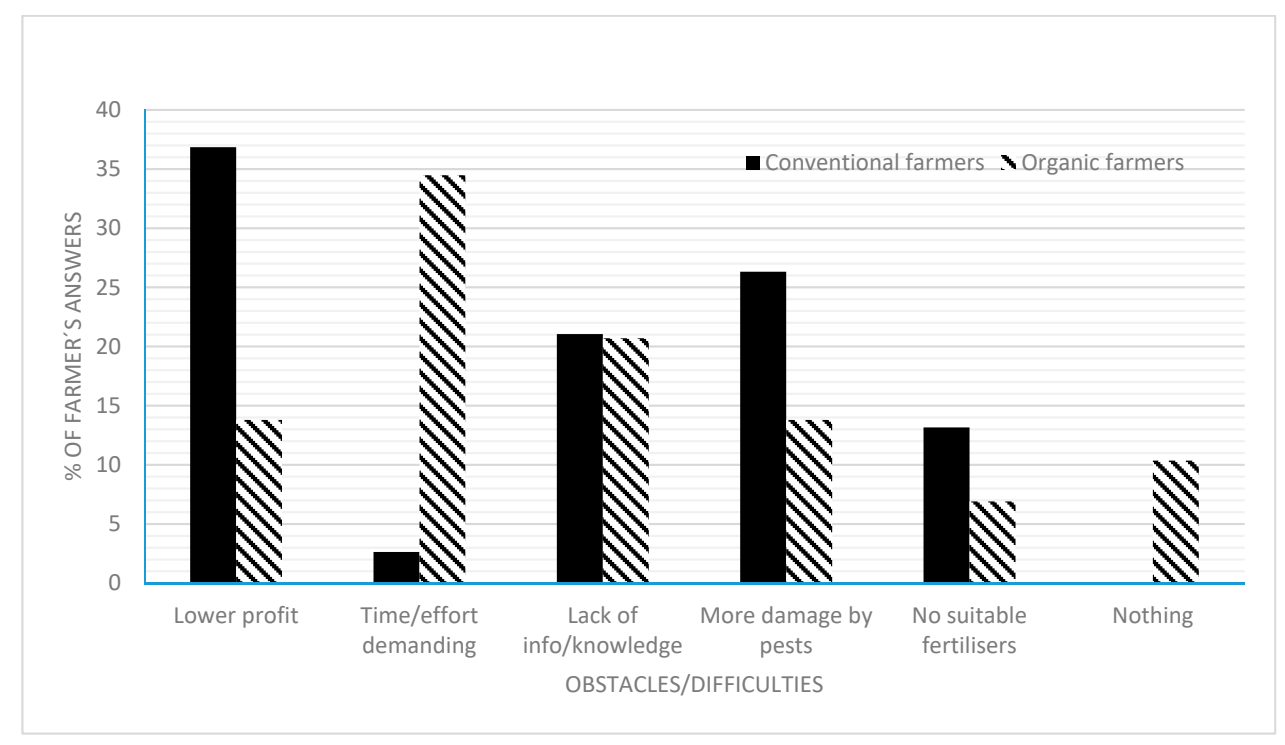

Figure 3. Difficulties with organic farming as perceived (open-ended question) by organic $(n=16)$ and conventional $(n=23)$ olive farmers in in Messenia, Greece.

Labor cost made up approximately $60 \%$ of the total production cost for both groups of farmers, which is similar to what was found among 375 Greece olive farms assessed by the Farm Accountancy Data Network [30].

Organic and conventional farmers used different fertilizers, except for the organically approved, nitrogen- and phosphorus-free fertilizer Patentkali, which was used by both groups. Most of the conventional farmers used traditional synthetic fertilizers, while most of the organic farmers used manure, compost and other organic methods (Figure 4). In both groups, some farmers used more than one fertilizer.

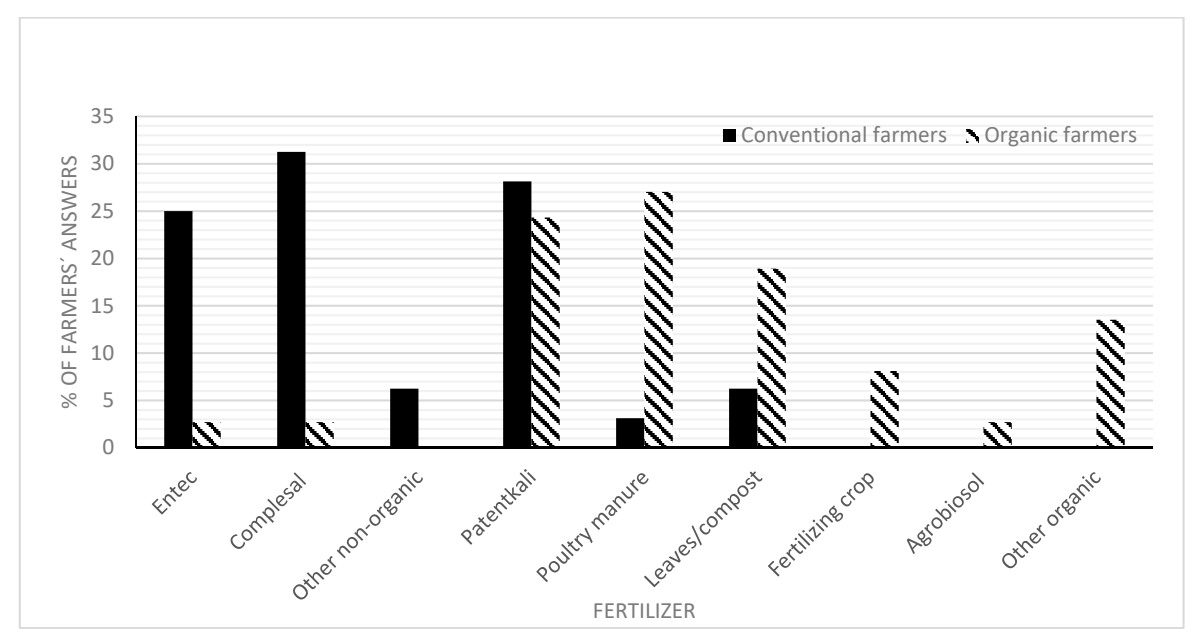

Figure 4. Fertilizers used by organic $(n=16)$ and conventional $(n=23)$ olive farmers in in Messenia, Greece. 
Many of the farmers, and especially conventional farmers, used several pesticides to combat different kinds of pests (Figure 5), while some $30 \%$ of the organic farmers used no pesticides at all. Conventional farmers were quite aware of the possible negative effects from pesticides and mentioned, for example, contamination of water and also that 'good' insects are killed by insecticides. One farmer mentioned that conventional agriculture has damaged the olive trees' natural defense against pests, making them dependent on pesticides. The most commonly used insecticide by conventional farmers was Dimethoate. Organic farmers only used substances approved in organic farming. Spinosyn A and D (in Success) and Pyrethrins can be considered as naturally-derived chemical pesticides, whereas e.g., Bacillus thuringensis is a biological defense and kaolin (in Surround) only works as a physical protection. Copper compounds were commonly used by both organic and conventional farmers as fungicides. No herbicides against weeds were used by the organic farmers.

Dacus oleae, also called the olive fly, was considered to be one of the most problematic pests by $40 \%$ of the farmers. Different kinds of fungi and the insects Calocoris trivialis (local name Kalokori) and Prays oleae (local name Pyrinotritis) were also considered as problematic.

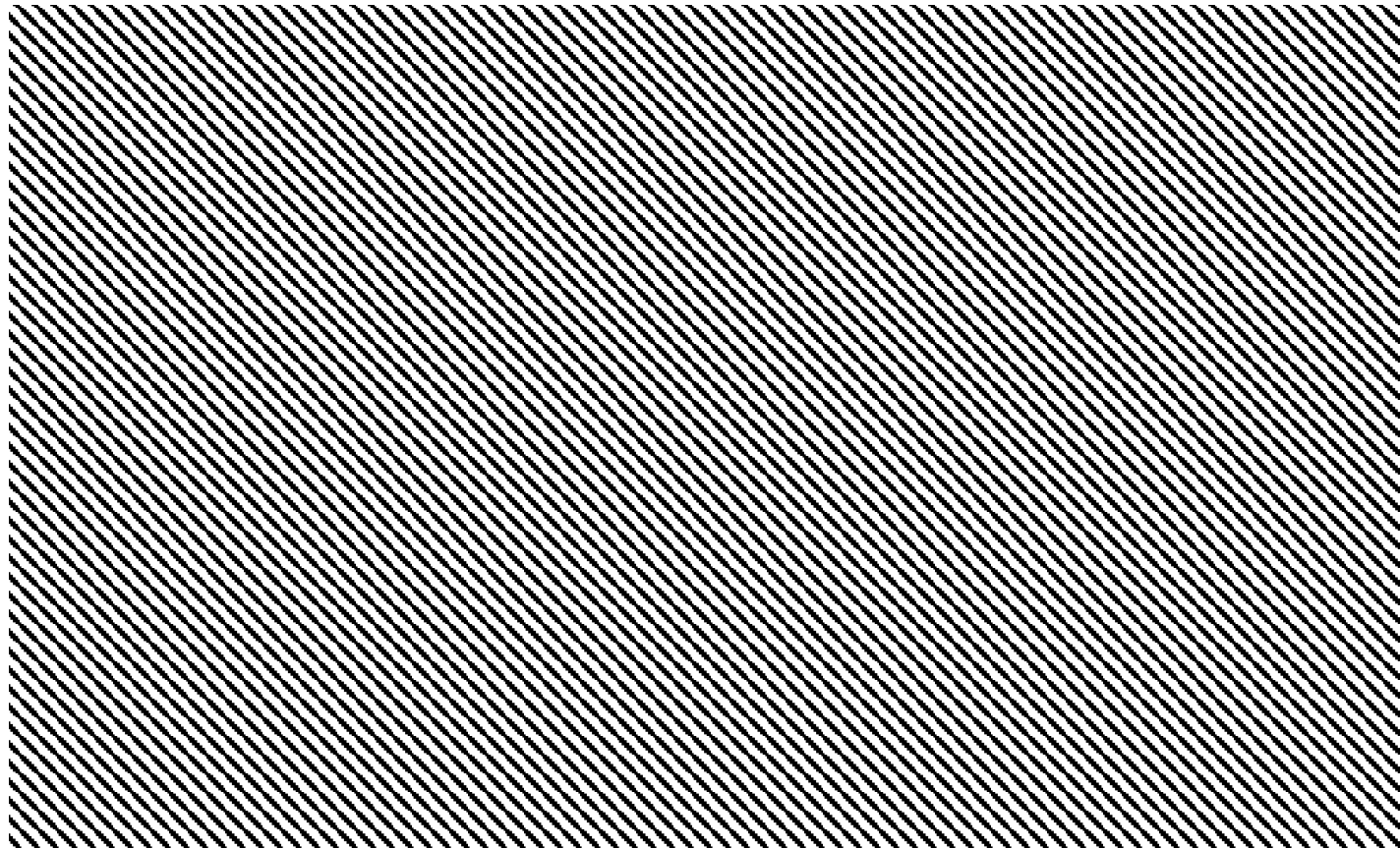

Figure 5. Pesticides (excluding herbicides used against weeds) used on olive trees by organic $(n=16)$ and conventional $(n=23)$ olive farmers in in Messenia, Greece.

All farmers used some kind of ground vegetation removal during part of the year. The reasons were mostly to facilitate the harvest, during which the olives are gathered and picked from the ground, and to keep away pests that breed in the humid environment created by the vegetation. Only conventional farmers used herbicides (Glyphosate) (Figure 6); $86 \%$ of the organic farmers used mowing as the only technique, which leaves a cover of short grass on the ground, while some $70 \%$ of the conventional farmers used either tillage or herbicides, which often leaves the soil bare (Figure 6). 


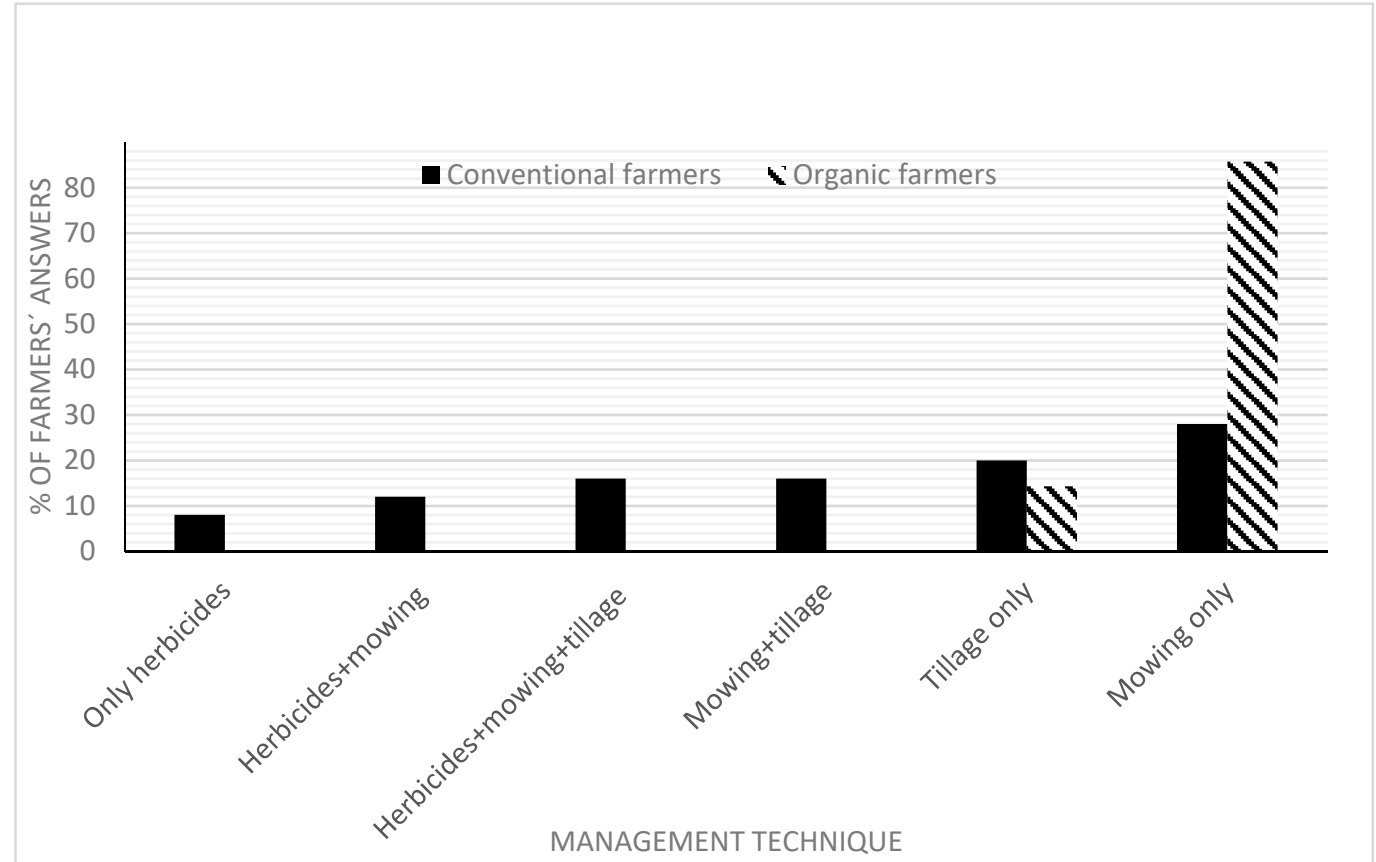

Figure 6. Ground vegetation management techniques among organic $(n=16)$ and conventional $(n=23)$ olive farmers in Messenia, Greece.

Agrochemicals constituted some $30 \%$ of the total cost accounted for in this study, where organic farmers had a significantly lower cost for pesticides but a slightly higher cost for fertilizers as compared to conventional farmers (Figure 7). The two groups of farmers had similar production costs (Figure 7), but organic olive farmers earned a significantly higher gross income from olive farming as compared to conventional farmers (Figure 8). The main reason for this was that they secured a significantly higher price for their olive oil as compared to the conventional farmers (Figure 8, Table 1). As a result the net income was significantly higher for organic farmers as compared to conventional farmers (Figure 8).

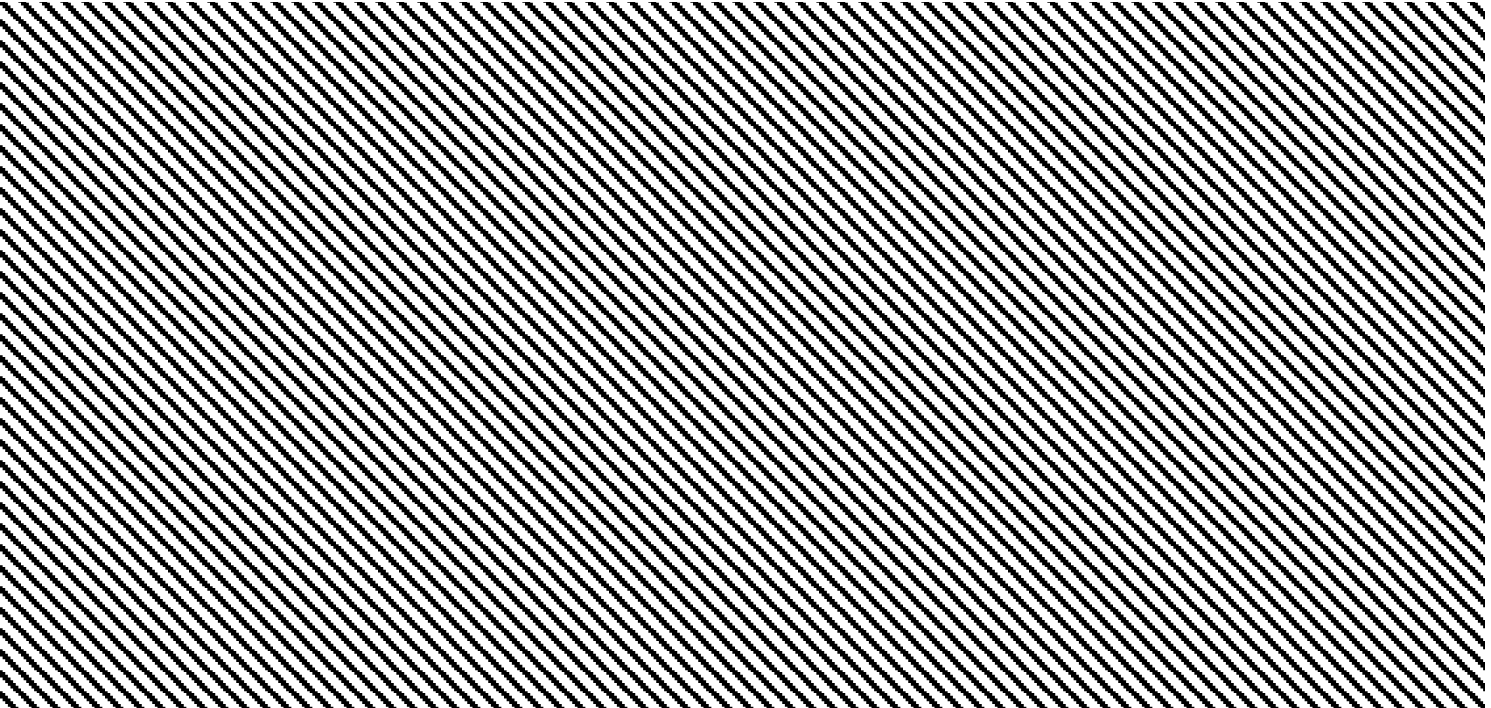

Figure 7. Annual cost of fertilizer and pesticides among organic $(n=16)$ and conventional $(n=23)$ olive farmers in Messenia, Greece. The error bars indicate standard deviations. The asterisk $\left({ }^{*}\right)$ marks statistically significant differences $(<0.05)$ between the two groups of farmers. 


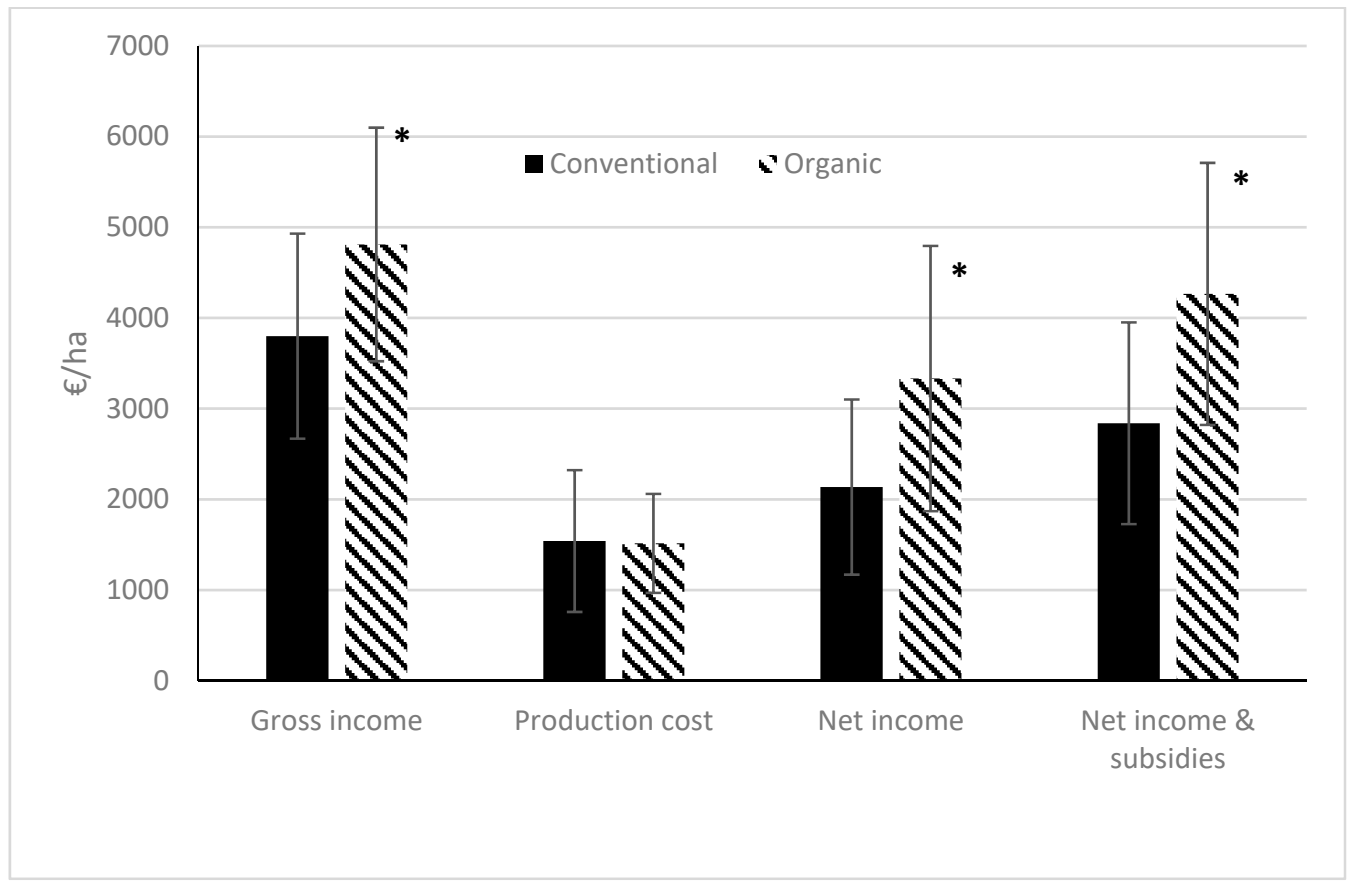

Figure 8. Annual income, costs and profits from olive oil production among organic $(n=16)$ and conventional $(n=23)$ olive farmers in Messenia, Greece. The error bars indicate the standard deviations. The asterisks $\left({ }^{*}\right)$ mark statistically significant differences $(<0.05)$ between the two groups of farmers.

Organic farmers also received somewhat higher subsidies as compared to conventional farmers, which further increased their profit (Table 1, Figure 8). A significantly larger proportion of the organic farmers' income came from olive farming ( $86 \%)$ as compared to conventional farmers $(66 \%)$ (Table 1$)$.

\section{Discussion}

Olive farming is deeply integrated in the nutritional, historical, and cultural identity of Greece. Olive farming and the olive oil industries also have a significant impact on the country's rural economy and the environment. Although some olive oil producers have embraced sustainable agriculture techniques to ensure the long-term health of both the industry and the environment, the overall trend is towards more intensive methods [4]. Still, organic farming and other integrated farming strategies could provide sustainable alternatives to more intensive farming strategies, recognizing that olive groves provide more benefits than just olives $[4,6]$.

Our results (Figures 4-8) showed that organic farming is both more environmentally and financially sustainable than conventional farming, which is in accordance with Romero-Gamez et al. [6], who found that organic farming showed the lowest impacts and that integrated production was the best olive production system from an overall environmental and productive point of view.

In our study organic farmers used less synthetic pesticides than conventional farmers, who mainly relied on pesticides, such as Glyphosate and Dimethoate, that have been linked to toxic effects on the environment and human health and also can contaminate the olive oil [31-33]. Likudis et al. [13] found that $56 \%$ of 70 olive oil samples from Greece contained pesticides, with an average of 2.25 pesticides per sample in the oil from the Peloponnese region. Amvrazi and Albanis [15] found Dimethoate in $80 \%$ of the samples of extra virgin oil from conventional olive farms in Peloponnese. They also found that $60 \%$ of the samples of organic olive oil contained pesticides and concluded that these pesticides could come from conventional farms. Even if all of the pesticide concentrations were far below the acceptable daily intake (ADI), and posed no risk for human consumption [15], high-quality olive oil should preferably not contain any pesticide at all. Many conventional farmers said that they would 
feel better providing consumers with organic products, and both groups of farmers agreed that organic farming contributed to a better health for both themselves and the consumers. Still, the fairly common use of copper compounds is also of some environmental concern among organic farmers [34].

The lower reliance on synthetic fertilizers among organic farmers also makes these operations more sustainable than conventional farming, although one could expect a leakage of nutrients from both systems. Romero-Gamez et al. [6] compared traditional systems with intensive and super-intensive olive farming systems in Spain, and found that fertilizers had the highest impact on the environment for all systems. The leakage of nutrients could be especially critical in coastal areas, where a good water quality is important for coastal-related activities, such as fisheries and tourism, which are important activities in Messenia. Thus, improved fertilization should be the first priority for optimizing olive growing, particularly in the organic systems, since manure fertilization, which was commonly used among the organic farmers in our study, can easily result in high costs and high environmental impacts if mismanaged [34].

Organic farmers also applied more environmentally-friendly ground vegetation management techniques (mowing), as compared to conventional farmers, who to a larger extent relied on tillage and herbicides [19,34]. Milgroom et al. [19] found that farms managed with tillage had the least vegetation cover, the highest erosion risks and the lowest SOM values. Soil managed by grazing livestock or mowing had the highest SOM values [19]. These aspects were also connected to the water infiltration rates [19], where increased infiltration decreases the runoff and thereby decreasing the erosion rates [35]. Pimentel et al. [35] made a comparison between organic and conventional corn and soybean fields, which showed that the runoff is lower in the organic fields, generating more groundwater recharge. More water was also retained in the organic soil because of a higher SOM content, which made a significant difference on the crop yields under drought conditions [35].

Our study also showed that organic olive farming provides a financially competitive alternative to conventional olive farming (Figure 8). This is a significant result because the common belief among the conventional farmers interviewed was that organic olive farming provided a lower profit than conventional farming, and this was seen as the major argument against organic olive farming. However, the results show that organic olive farmers neither obtain significantly lower yields nor have higher production costs than conventional olive farmers, and that the profitability is significantly higher for the organic farmers. These results are in line with Sgroi et al.'s [20] cost-benefit analysis of organic and conventional olive farming in Sicily, Italy, where they concluded that organic olive farming was more profitable both with and without the extra subsidies that organic farmers received. In the study by Sgroi et al. [20], though, organic olive farming had a lower oil yield $(659 \mathrm{~kg} / \mathrm{ha})$ than conventional farming $(899 \mathrm{~kg} / \mathrm{ha})$, which was not seen in our study, where the oil yield was similar between the two farming categories.

Paydar et al. [21] compared the economic performance of organic and conventional olive farming in Rudbar, Iran. Unlike the results of the present study, they found no significant difference in the profitability between organic and conventional farms [21]. The production costs were significantly lower for the organic farmers, but so was the production value. In the local market of Rudbar there was, however, no price difference between organic and conventional olives, which was the case in our study.

The price difference for olive oil from organic and conventional olive farming is a major factor contributing to the higher profitability in organic olive farming [20,34]. This indicates the importance and potential that organic farming strategies have to protect and even further develop the high quality of the olive oil produced in the region. Being recognized as a Protected Designation of Origin (PDO) is a competitive advantage against other olive producers and creates a demand and market for high-quality olive oil from the region that is considered as extra fine, which should be managed with care. According to Klonaris and Agiangkatzoglou [2], there is a small, but growing percentage of consumers who are willing to pay quite dearly for top quality olive oil, and this a may be an important way for Greek olive farmers to compete in the olive oil market. It is well known that Greece enjoys 
a higher share of high-quality extra virgin olive oil (almost $80 \%$ of its total production), which is considered as a premium product in the international market [2]. One of the objectives of PDO is to improve the income of farmers, in return for a "genuine effort to improve quality". This objective fits well with the strategies for organic olive farming in Messenia, where a more selective use or agrochemicals safeguard a high quality olive oil, which in return generates a higher price and profit for organic olive oil.

Organic farmers were more aware of the higher demand for organic olive oil than conventional farmers. This awareness of the higher price and demand for organic olive oil is critical for creating a 'mind-set' where sustainable production strategies are seen as an important way to increase profitability, and it was quite surprising that conventional farmers seemed to be more aware of the health and environmental benefits than the financial benefits with organic olive farming. Still, with a trend of increased tourism in the study area, it is likely that this demand for organic-certified olive products will increase even further in the future and could provide an important mechanism to further stimulate organic olive production, especially if conventional farmers increasingly would recognize that organic farming could be a way to increase rather than decrease profitability. Sustainable innovation would in this sense increase production efficiency and economic performance [1]. This in turn would indirectly contribute to environmental and health benefits for the region, which in the long run may be even more important than the short-term financial gains.

Iofrida et al. [1] recently found that many actors involved in olive farming in Italy perceived a need to orient Calabrian olive growing towards more sustainable management practices, by better exploiting its potential and focusing on product quality. This may be even more important in Messenia, where the morphology of the landscape is an obstacle for 'mechanized' harvesting, which is commonly applied in Spain and Italy. The production of high-quality olive oil may be one of the few ways for Messenia to compete with other olive oil-producing countries, which may be better suited for the production of high quantities.

Thus, there is a promising potential for enhanced organic olive farming in Messenia, which would provide a sustainable alternative to conventional olive farming. Our study showed that most farmers already perceive major environmental and health benefits from organic farming. They also feel that it enhances the quality of the olive oil. Twenty percent of the conventional farmers were interested in starting organic farming and another $50 \%$ were uncertain. Thus, more information, similar to this study, that shows that organic olive farming also is at least as profitable as conventional olive farming, could be critical to convince more farmers to start with organic olive farming. However, there is also a need to provide technical know-how and information to farmers about, for example, alternative pesticides and fertilizers, so they can more easily start with organic farming. New innovative agricultural systems should not only consist of new technical or organizational solutions; a core issue in sustainable innovation is also about how knowledge is produced and shared [5]. Processes should be innovated by connecting scientific research, stakeholders, local actors and policy makers and fostering participation and collaboration between these different types of actors [36].

The time demand was also mentioned as a difficulty with organic farming by several organic farmers, although this was not mentioned by the conventional farmers. Still, this might imply that the conversion to organic farming is mostly applicable to full-time, or nearly full-time, farmers. However, it could also be argued that more farmers would be able to work full-time with their olive cultivation if they get a higher profit by applying organic farming strategies. Some organic farmers also said that they enjoyed allocating extra time and effort to their farms. They felt good about taking care of the farms, and it made them feel a stronger connection to their farms and prouder about their products. This 'mind-set', coupled with convincing proof that organic olive oil production not only provides environmental and health benefits, but also provides higher quality products, which are in higher demand and more profitable than conventional olive farming, is needed to further expand organic olive farming in Messenia. This would probably not only make financial sense to the individual 
farmers, but also contribute to a diversification of production systems and enhance the environmental quality of the whole region over time.

\section{Conclusions}

This study shows that organic olive farming in south-western Messenia is both more environmentally and financially sustainable than conventional olive farming. Organic farmers use less toxic pesticides and mineral fertilizers than conventional farmers and also apply more environmentally friendly ground management techniques. Both groups of farmers believed that organic farming was better for the health, the environment and the quality of the olive oil. The yield and production costs were similar between the two farming systems, but the income and profit were significantly higher for the organic farmers, primarily because of a higher price and subsidies for organic olive oil. Despite this, conventional farmers perceived a low profit as the major constraint to organic farming. All farmers agreed that there was a need for more information and knowledge about organic farming to expand these activities in the area.

Author Contributions: Conceptualization, H.B., G.M. and A.S.E.; Analysis, A.S.E., H.B. and G.M.; Investigation, A.S.E., G.M. and H.B.; Data Curation, A.S.E. and H.B.; Writing-Original Draft Preparation, A.S.E.; Writing-Review and Editing, H.B., A.S.E., G.M.; Visualization, A.S.E., H.B., G.M.; Supervision, H.B. and G.M.

Funding: This research did not receive any specific grant from funding agencies in the public, commercial, or not-for-profit sectors.

Acknowledgments: Valuable help and comments were provided by Sotiris Tsekas, agronomist of TEMES SA (Developers of Costa Navarino), Giorgos Paraskevopoulos, a local agronomist and Giorgos Kokkinos, farmer and President of Nileas, a local cooperative of farmers. We are also grateful for the help provided by Ilektra Theodorakea and all the farmers who patiently participated in the interviews. Research facilities and travel support was provided by the Navarino Environmental Observatory (NEO). Valuable comments were provided by two anonymous reviewers.

Conflicts of Interest: The authors declare no conflicts of interest.

\section{References}

1. Iofrida, N.; De Luca, A.I.; Gulisano, G.; Strano, A. An application of Q-methodology to Mediterranean olive production-Stakeholders' understanding of sustainability issues. Agric. Syst. 2018, 162, 46-55. [CrossRef]

2. Klonaris, S.; Agiangkatzoglou, A. Competitiveness of Greek virgin olive oil in the main destination markets. Br. Food J. 2018, 120, 80-95. [CrossRef]

3. Tsarouhas, P.; Achillas, C.; Aidonis, D.; Folinas, D.; Maslis, V. Life Cycle Assessment of olive oil production in Greece. J. Clean. Prod. 2015, 93, 75-83. [CrossRef]

4. Camarsa, G.; Gardner, S.; Jones, W.; Eldridge, J.; Hudson, T.; Thorpe, E.; O'Hara, E. LIFE among the Olives: Good Practice Guide in Improving Environmental Performance in the Olive Oil Sector; European Union: Luxemburg, 2010; Available online: http:/ / ec.europa.eu/environment/life/publications/lifepublications / lifefocus / documents/oliveoil.pdf (accessed on 7 July 2018).

5. De Luca, A.I.; Falcone, G.; Stillitano, T.; Iofrida, N.; Strano, A.; Gulisano, G. Evaluation of sustainable innovations in olive growing systems: A Life Cycle Sustainability Assessment case study in southern Italy. J. Clean. Prod. 2018, 171, 1187-1202. [CrossRef]

6. Romero-Gamez, M.; Castro-Rodríguez, J.; Suarez-Rey, E.M. Optimization of olive growing practices in Spain from a life cycle assessment perspective. J. Clean. Prod. 2017, 149, 25-37. [CrossRef]

7. Tuck, S.L.; Winqvist, C.; Mota, F.; Ahnström, J.; Turnbull, L.A.; Bengtsson, J. Land-use intensity and the effects of organic farming on biodiversity: A hierarchical meta-analysis. J. Appl. Ecol. 2014, 51, 746-755. [CrossRef] [PubMed]

8. EC. Council Regulation (EC) No. 834/2007 of 28 June 2007 on Organic Production and Labelling of Organic Products and Repealing Regulation (EEC) No. 2092/91. 2007, pp. 1-23. Available online: https:/ / eur-lex.europa. eu/legal-content/EN/TXT/PDF/?uri=CELEX:32007R0834\&from=EN (accessed on 7 July 2018).

9. Lernoud, J.; Willer, H. Organic Agriculture Worldwide: Area, Operators and Market. In the World of Organic Agriculture: Statistics and Emerging Trends 2017; FiBL and IFOAM—Organics International: Frick, Switzerland, 2017. 
10. European Union. Facts and Figures on Organic Agriculture in the European Union; Agriculture and Rural Development: Brussel, Belgium, 2013; Available online: https: / /ec.europa.eu/agriculture/sites/agriculture/ files/markets-and-prices/more-reports/pdf/organic-2013_en.pdf (accessed on 7 July 2018).

11. Lo Gullo, M.A.; Salleo, S. Different strategies of drought resistance in three Mediterranean sclerophyllous trees growing in the same environmental conditions. New Phytol. 1988, 108, 267-276. [CrossRef]

12. Angerosa, F.; Di Giacinto, L.; Solinas, M. Influence of Dacus oleae infestation on flavor of oils, extracted from attacked olive fruits, by HPLC and HRGC analyses of volatile compounds. Grasas Aceites 1992, 43, 134-142. [CrossRef]

13. Likudis, Z.; Costarelli, V.; Vitoratos, A.; Apostolopoulos, C. Determination of pesticide residues in olive oils with protected geographical indication or designation of origin. Int. J. Food Sci. Technol. 2014, 49, 484-492. [CrossRef]

14. Pucci, C.; Ballatori, E.; Tirimbelli, D.; Ambrosi, G. Optimization of the olive harvest in years of high infestation. Frustula Entomol. 1982, 5, 3-30.

15. Amvrazi, E.G.; Albanis, T.A. Pesticide residue assessment in different types of olive oil and preliminary exposure assessment of Greek consumers to the pesticide residues detected. Food Chem. 2009, 113, 253-261. [CrossRef]

16. Campos, M.; Fernández, L.; Ruano, F.; Cotes, B.; Cárdenas, M.; Castro, J. Short term response of ants to the removal of ground cover in organic olive groves. Eur. J. Entomol. 2011, 108, 417-423. [CrossRef]

17. Castro-Caro, J.C.; Barrio, I.C.; Tortosa, F.C. Is the effect of farming practices on songbird communities landscape dependent? A case study of olive groves in southern Spain. J. Ornitol. 2014, 155, 357-365. [CrossRef]

18. Moreno, B.; Garcia-Rodriguez, S.; Cañizares, R.; Castro, J.; Benítez, E. Rainfed olive farming in south-eastern Spain: Long-term effect of soil management on biological indicators of soil quality. Agric. Ecosyst. Environ. 2009, 131, 333-339. [CrossRef]

19. Milgroom, J.; Soriano, M.A.; Garrido, J.M.; Gómez, J.A.; Fereres, E. The influence of a shift from conventional to organic olive farming on soil management and erosion risk in Southern Spain. Renew. Agric. Food Syst. 2007, 22, 1-10. [CrossRef]

20. Sgroi, F.; Foderà, M.; Di Trapani, A.M.; Tudisca, S.; Testa, R. Cost-Benefit Analysis: A comparison between conventional and organic olive growing in the Mediterranean Area. Ecol. Eng. 2015, 82, 542-546. [CrossRef]

21. Paydar, L.; Firouzi, S.; Aminpanah, H. The economic performance of organic and conventional olive orchards in Iran. Idesia (Arica) 2015, 33, 109-113. [CrossRef]

22. Artukoglu, M.M.; Olgun, A.; Adanacioglu, H. The efficiency analysis of organic and conventional olive farms: Case of Turkey. Agric. Econ. 2010, 56, 89-96. [CrossRef]

23. Beaufoy, G. The Environmental Impact of Olive Oil Production in the European Union: Practical Options for Improving the Environmental Impact. European Forum on Nature Conservation and Pastoralism and the Asociación para el Análisis y Reforma de la Política Agro-Rural. 2000. Available online: http: / / ec.europa.eu/environment/agriculture/pdf/oliveoil.pdf (accessed on 7 July 2018).

24. Giannopoulou, A. The Economical Development of the Greek Olive-Oil Industry with Special Reference to Messenia Province. Ph.D. Thesis, Department of Economics, University of Salford, Manchester, UK, 1990.

25. Nationalencyklopedin, Messenien. 2017. Available online: http://www.ne.se/uppslagsverk/encyklopedi/ lång/messenien (accessed on 22 May 2017).

26. Hellenic Statistical Authority. Distribution of Utilized Agricultural Area, by Basic Categories of Land Use by Region and Department. E04. 2009. Available online: https:/ /www.statistics.gr/en/statistics/-/ publication/SPG31/ (accessed on 21 February 2018).

27. Kottek, M.; Grieser, J.; Beck, C.; Rudolf, B.; Rubel, F. World Map of the Köppen-Geiger climate classification updated. Meteorol. Z. 2006, 15, 259-263. [CrossRef]

28. Radinovsky, L. Kalamata PDO Expands to All of Messinia. Olive Oil Times. 2015. Available online: https: //www.oliveoiltimes.com/olive-oil-making-and-milling/kalamata-pdo-expands-messinia/48388 (accessed on 7 July 2018).

29. Warren, C.A.B. Qualitative Interviewing. In Handbook of Interview Research; Gubrium, J.F., Holstein, J.A., Eds.; SAGE: Thousand Oaks, CA, USA, 2002. 
30. EC. EU Olive Oil Farms Report-Based on FADN Data. European Commission. Directorate-General for Agriculture and Rural Development. Directorate, L. Economic Analysis, Perspectives and Evaluations L.3. Microeconomic Analysis of EU Agricultural Holdings. 2012. Available online: http:/ / ec.europa.eu/ agriculture/rica/pdf/Olive_oil\%20_report2000_2010.pdf (accessed on 7 July 2018).

31. Alavanja, M.C.R.; Hoppin, J.A.; Kamel, F. Health Effects of Chronic Pesticide Exposure: Cancer and Neurotoxicity. Annu. Rev. Public Health 2004, 25, 155-197. [CrossRef] [PubMed]

32. Tsui, M.T.K.; Chu, L.M. Aquatic toxicity of glyphosate-based formulations: Comparison between different organisms and the effects of environmental factors. Chemosphere 2003, 52, 1189-1197. [CrossRef]

33. Eskenazi, B.; Bradman, A.; Castorina, R. Exposures of children to organophosphate pesticides and their potential adverse health effects. Environ. Health Perspect. 1999, 107, 409-419. [CrossRef] [PubMed]

34. Mohamad, R.S.; Verrastro, V.; Cardone, G.; Bteich, M.R.; Favia, M.; Moretti, M.; Romac, R. Optimization of organic and conventional olive agricultural practices from a Life Cycle Assessment and Life Cycle Costing perspectives. J. Clean. Prod. 2014, 70, 78-89. [CrossRef]

35. Pimentel, D.; Hepperly, P.; Hanson, J.; Douds, D.; Seidel, R. Environmental, Energetic, and Economic Comparisons of Organic and Conventional Farming Systems. Bioscience 2005, 63, 573-582. [CrossRef]

36. Triomphe, B.; Rajalahti, R. From concept to emerging practice: What does a innovation system perspective bring to agricultural and rural development. In Renewing Innovation Systems in Agriculture and Food: How to Go towards More Sustainability? Coudel, E., Devautour, H., Soulard, C.T., Faure, G., Hubert, B., Eds.; Wageningen Academic Publishers: Wageningen, The Netherlands, 2013; pp. 57-76.

(C) 2018 by the authors. Licensee MDPI, Basel, Switzerland. This article is an open access article distributed under the terms and conditions of the Creative Commons Attribution (CC BY) license (http:/ / creativecommons.org/licenses/by/4.0/). 